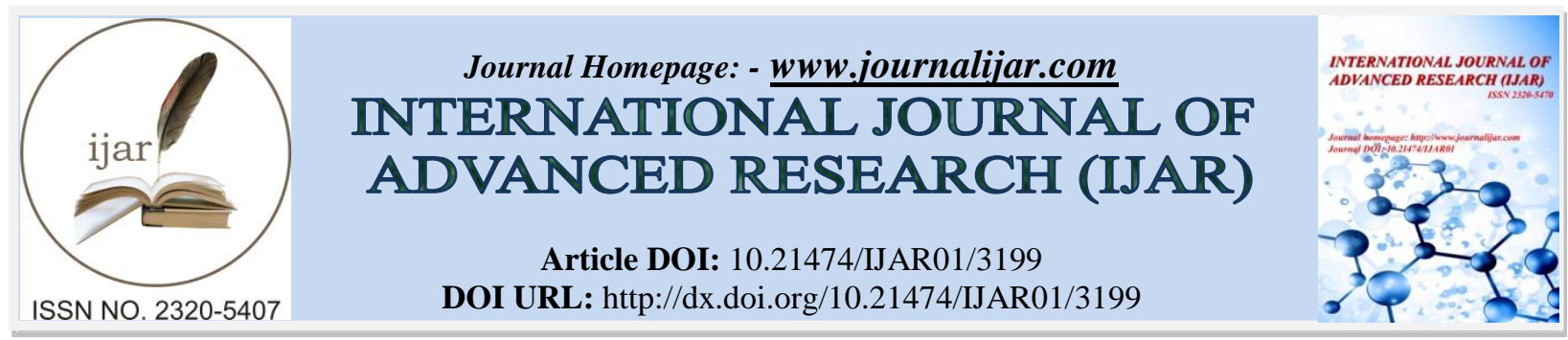

RESEARCH ARTICLE

\title{
HISTOPATHOLOGICAL STUDY OF OPHTHALMIC LESIONS.
}

${ }^{*}$ Gupta $S^{1}$, Paricharak D.G. ${ }^{2}$, Inamdar A.A. ${ }^{3}$, Verma A ${ }^{4}$, Ghatge $R M^{5}$ and Sujata $N^{6}$.

1. Post graduate student, Department of Pathology, D.Y. Patil Medical College, Kolhapur.

2. Associate Professor, Department of Pathology, D.Y. Patil Medical College, Kolhapur.

\section{Manuscript Info}

Manuscript History

Received: 18 December 2016

Final Accepted: 17 January 2017

Published: February 2017

Key words:-

Ophthalmic Pathology, Eyelids,

Conjunctiva.

\section{Abstract}

Ophthalmic pathology is the subspecialty of pathology. It is unique in many respects as it encompasses wide range of tissues, epithelial elements, connective tissue and specialized tissues. The present study focused on most common ophthalmic lesions and to establish their accurate pathological diagnosis. The study was conducted in department of Pathology in collaboration with department of Ophthalmology, Dr. D. Y. Patil Medical College, Hospital and Research Centre, Kolhapur, on 132 cases of ophthalmic lesions received in the Histopathology laboratory during period from May 2014 to April 2016. Ophthalmic specimens were routinely processed and H\& E stain was performed. The study concluded that, ophthalmic lesions reported were mostly non-neoplastic. Eyelid was the commonest site followed by cornea and conjunctiva. A wide range of lesions including some rare conditions like retinoblastoma, were studied on various parameters and histopathological features were highlighted. Many neoplastic conditions clinically mimic other less aggressive neoplastic or inflammatory conditions and needs differentiation before definitive therapy is planned. So, to establish their accurate diagnosis, histopathological correlation is important and mandatory.

Copy Right, IJAR, 2017,. All rights reserved.

\section{Introduction:-}

Eye is a heterogenous tissue; hence we tend to see a variety of lesions, both non-neoplastic and neoplastic with tumoral types and subtypes. It is unique in many respects as it encompasses wide range of tissues, epithelial elements, connective tissue and specialized tissue. ${ }^{1}$ The goal of the Ophthalmic pathology service is to enhance communication between the ophthalmic surgeon and the pathology laboratories. ${ }^{2}$ Eye and ocular adnexa is composed of eyelids, lacrimal passages and glands, orbit, conjunctiva, cornea, sclera and intraocular tissue, mainly retina, choroid plexus, iris, etc. Ophthalmic lesions are divided into non neoplastic and neoplastic. Non neoplastic lesions include the developmental anomalies, inflammatory diseases and degenerative diseases. Neoplastic lesions are benign and malignant. ${ }^{3}$

Ophthalmic specimens submitted for histopathologic evaluation are obtained mostly from eyelids. ${ }^{4}$ Among eyelid lesions, dermoid cyst is commonest, followed by epidermal inclusion cyst, intradermal nevus, sebaceous (meibomian) carcinoma, skin carcinomas (basal cell carcinoma, squamous carcinoma, accessory glands carcinomas, 
and malignant melanoma). ${ }^{5}$ The knowledge of corneal pathology is limited. The most common diseases are endothelial decompensation, fibrosis and vascularization. Conjunctival tumors are one of the most frequent of the eye and adnexa. They comprise a large variety of conditions, from benign lesions such as nevus or papilloma, to malignant lesions such as epidermoid carcinoma or melanoma. ${ }^{6}$ Lacrimal gland lesions include inflammatory pseudotumor, malignant lymphoma, and leukemia. Among the epithelial tumors, benign mixed cell tumor (pleomorphic adenoma) is the most common. ${ }^{7}$ Melanomas arising from the pigmented or potentially pigment producing cells of the uvea are the most frequent primary intraocular neoplasms in adults. ${ }^{8}$ Retinoblastoma is the most common primary malignancy of young children. ${ }^{9}$ The histopathological diagnosis of the diseases plays an important part in patient care.

\section{Methodology:-}

The present study was conducted in the Department of Pathology at Dr. D. Y. Patil Medical College, Hospital and Research Institute, Kolhapur. This is a prospective study conducted for a period of 2 years from May 2014 to April 2016. The patients were selected at random irrespective of age, sex, socioeconomic status and residence. The eligible patients were briefed about the nature of the study and a written informed consent was obtained from the selected patients. Findings were recorded on predesigned proforma. All the biopsies related to the ocular site were included; the tissue samples included enucleated eyes, excision biopsies, corneal buttons, fine needle aspiration biopsies and intact tissue biopsies. The samples were processed according to the standard protocol and stained with routine technique and Haematoxylin \& Eosin staining was performed. Histopathological interpretation was made by correlation of provided clinical data, studying of gross morphology and light microscopic examination.

\section{Results:-}

In present study of 132 cases, 67 cases (50.75\%) were males and 65 cases (49.25\%) were females with male to female ratio of 1.03:1 suggesting a slight male preponderance. The most common age group in our study was 41 to 50 years with a total of twenty cases $(20.45 \%)$ out of the total cases. Ophthalmic lesions we received were mostly non neoplastic (79 cases, 59.86\%) and 40.14\% (53cases) were neoplastic. Out of the neoplastic lesions $30.30 \%$ (40 cases) were benign and $9.34 \%$ (13 cases) were malignancies. Site wise distribution showed maximum number of lesions were from eyelids (48 cases,36.35\%). Conjunctiva was the second commonest site (38 cases, 28.77\%) followed by corneal lesions (34 cases, 25.74\%); orbital lesions (5 cases, 3.77\%) and lesions from intraocular tissues (4 case, $3.03 \%$ ). Lesions from lacrimal gland and passages were least common.

Twenty seven cases $(56.25 \%)$ were non neoplastic eyelid lesions and fourteen cases $(29.17 \%)$ were benign eyelid lesions out of the 48 eyelid lesions. Majority of the cases were Inclusion cysts (11 cases, 40.74\%), Nevocellular nevus (6 cases, $42.85 \%$ ). Seven cases (14.58\%) were malignant eyelid lesions out of the 48 eyelid lesions. Majority of the cases were Squamous cell carcinoma (4 cases, 57.14\%), followed by Basal cell carcinoma (2 cases,28.57\%).

Thirty eight lesions were received from conjunctiva. Majority were diagnosed as CIN (14 cases, 36.85\%), followed by, Pterygium, Squamous cell carcinoma and conjunctival papilloma. Thirty four cases were received from corneal lesions. Majority were diagnosed as Suppurative and inflammatory lesions (26 cases, 76.47\%). Five lesions were received from orbit. Of the 5 cases, three cases were diagnosed as Epidermal cyst (3 cases, 60\%), one case of Neurofibroma (20\%) and one case of Basal cell carcinoma (20\%). Only 4 cases were from intraocular tissues, one case each $(25 \%)$ of Retinoblastoma, Macular amyloidosis, Massive retinal gliosis and Choroid suppurative lesion were reported. Retinoblastoma, a rare paediatric tumor seen in 4years old was also received in this study. Three cases were received from lacrimal gland and passages.

Table 1:- Distribution of lesions as neoplastic and non - neoplastic

\begin{tabular}{|l|l|l|l|}
\hline \multicolumn{2}{|l|}{ Lesions $(\mathrm{n}=132)$} & No. of cases & Percentage (\%) \\
\hline Non-neoplastic & 79 & $59.86 \%$ \\
\hline \multirow{2}{*}{ Neoplastic } & Benign & 40 & $30.30 \%$ \\
\cline { 2 - 4 } & Malignant & 13 & $9.84 \%$ \\
\hline Total & 132 & $100 \%$ \\
\hline
\end{tabular}


Table 2:- Site wise distribution of ophthalmic lesions

\begin{tabular}{|l|l|l|}
\hline SITE & NUMBER & PERCENTAGE(\%) \\
\hline Eyelid & 48 & $36.35 \%$ \\
\hline Conjunctiva & 38 & $28.77 \%$ \\
\hline Cornea & 34 & $25.74 \%$ \\
\hline Orbit & 5 & $3.77 \%$ \\
\hline Intraocular Tissues & 4 & $3.03 \%$ \\
\hline Lacrimal Gland And Passages & 3 & $2.72 \%$ \\
\hline TOTAL & $\mathbf{1 3 2}$ & $\mathbf{1 0 0 \%}$ \\
\hline
\end{tabular}

Table 3:- Shows distribution of various eyelid lesions.

\begin{tabular}{|c|c|}
\hline \multicolumn{2}{|c|}{ DISTRIBUTION OF DIFFERENT EYELID LESIONS $(n=48)$} \\
\hline \multicolumn{2}{|c|}{ NON NEOPLASTIC (27 cases, 56.25\%) \& BENIGN (14cases, 29.17\%) LESIONS } \\
\hline INCLUSION CYSTS (EPIDERMOID) & $11(22.91 \%)$ \\
\hline NEVOCELLULAR NEVUS & $6(1.25 \%)$ \\
\hline DERMOID CYSTS & $3(6.25 \%)$ \\
\hline SQUAMOUS PAPILLOMA & $2(4.16 \%)$ \\
\hline BENIGN ADNEXAL TUMOR & $2(4.16 \%)$ \\
\hline CHALAZION & $2(4.16 \%)$ \\
\hline HIDROCYSTOMA & $1(2.08 \%)$ \\
\hline OTHER BENIGN AND INFLAMMATORY LESIONS & $14(29.14 \%)$ \\
\hline \multicolumn{2}{|c|}{$\begin{array}{l}\text { MALIGNANT LESIONS (7cases, } 14.58 \% \text { ) } \\
\end{array}$} \\
\hline BASAL CELL CARCINOMA & $2(4.16 \%)$ \\
\hline SQUAMOUS CELL CARCINOMA & $4(8.33 \%)$ \\
\hline MEIBOMIAN GLAND CARCINOMA & $1(2.08 \%)$ \\
\hline
\end{tabular}

Table 4:- Distribution of conjunctival lesions

\begin{tabular}{|c|c|c|c|}
\hline \multirow{2}{*}{\multicolumn{2}{|c|}{ Disease }} & \multicolumn{2}{|c|}{ Distribution(n=38) } \\
\hline & & No. of cases & Percentage \\
\hline \multicolumn{2}{|l|}{ Pterygium } & 4 & 10.53 \\
\hline \multicolumn{2}{|l|}{ Hemangioma } & 3 & 7.89 \\
\hline \multicolumn{2}{|l|}{ Conjunctival cyst } & 2 & 5.26 \\
\hline \multicolumn{2}{|l|}{ Rhinosporidiosis } & 1 & 2.63 \\
\hline \multicolumn{2}{|l|}{ Conjunctival Papilloma } & 4 & 10.53 \\
\hline \multicolumn{2}{|l|}{ Sebacious Hyperplasia } & 1 & 2.63 \\
\hline \multicolumn{2}{|l|}{ Mild Epithelial Dysplasia } & 2 & 5.26 \\
\hline \multirow{3}{*}{$\begin{array}{l}\text { Conjunctival } \\
\text { intraepithelial neoplasia } \\
(\mathrm{CIN})\end{array}$} & CIN I & 5 & 13.16 \\
\hline & CIN II & 7 & 18.43 \\
\hline & CIN III & 2 & 5.26 \\
\hline \multicolumn{2}{|l|}{ Squamous Cell Carcinoma } & 4 & 10.53 \\
\hline \multicolumn{2}{|c|}{ Non Specific Inflammations \& Granulation Tissues } & 3 & 7.89 \\
\hline \multicolumn{2}{|l|}{ Total } & 38 & 100 \\
\hline
\end{tabular}

Table 5:- shows distribution of various lesions of other sites.

\begin{tabular}{|l|l|}
\hline \multicolumn{1}{|c|}{ DISTRIBUTION OF LESIONS OF OTHER SITES } \\
\hline CORNEAL ULCER & $\mathbf{2}$ \\
\hline STAPHYLOMA & $\mathbf{1}$ \\
\hline DYSTROPHIES (FUCH'S\&LATTICE) & $\mathbf{3}$ \\
\hline KERATOGLOBUS & $\mathbf{1}$ \\
\hline PANNUS & $\mathbf{1}$ \\
\hline OTHER SUPPURATIVE \&INFLAMMATORY LESIONS & $\mathbf{2 6}$ \\
\hline \multicolumn{2}{|c|}{ INTRAOCULAR LESIONS (4cases, 3.03\%) } \\
\hline RETINOBLASTOMA & $\mathbf{1}$ \\
\hline
\end{tabular}




\begin{tabular}{|l|l|}
\hline MACULAR AMYLOIDOSIS & $\mathbf{1}$ \\
\hline RETINAL GLIOSIS & $\mathbf{1}$ \\
\hline CHOROID SUPPURATIVE LESION & $\mathbf{1}$ \\
\hline \multicolumn{1}{|c|}{ ORBITAL (5cases , 3.77\%) \& LACRIMAL (3 cases, 2.72\%) LESIONS } & $\mathbf{1}$ \\
\hline BASAL CELL CARCINOMA & $\mathbf{4}$ \\
\hline EPIDERMAL CYST & $\mathbf{1}$ \\
\hline NEUROFIBROMA & $\mathbf{2}$ \\
\hline OTHER LESIONS & \\
\hline
\end{tabular}

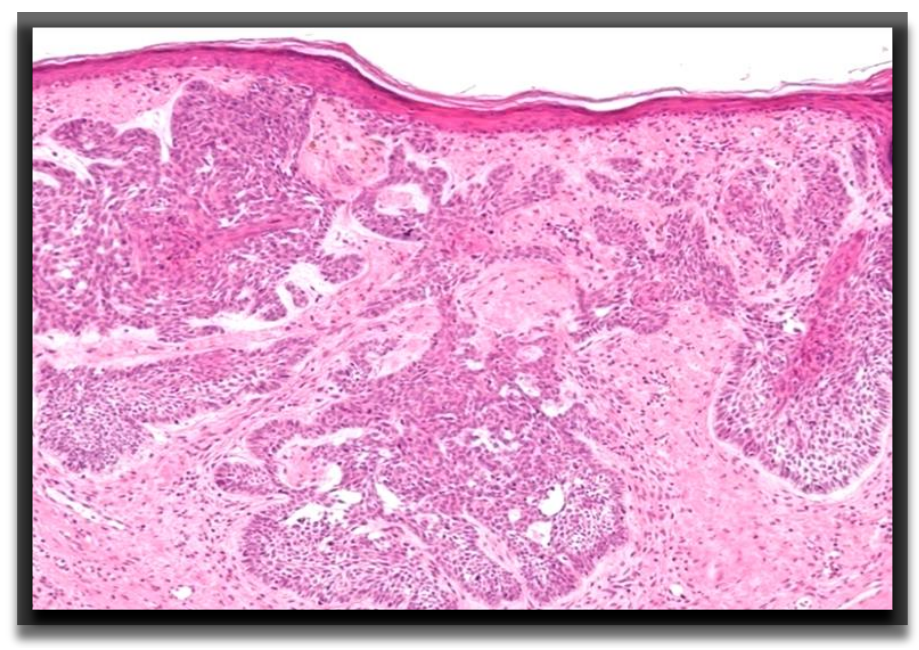

Figure 1:- BASAL CELL CARCINOMA: Section shows (H\&E stain; X4) nests of varying sizes formed by atypical basaloid cells surrounded by a sharply demarcated desmoplastic stroma. Peripheral palisading, peritumoral clefting along with few mitotic figures are seen.
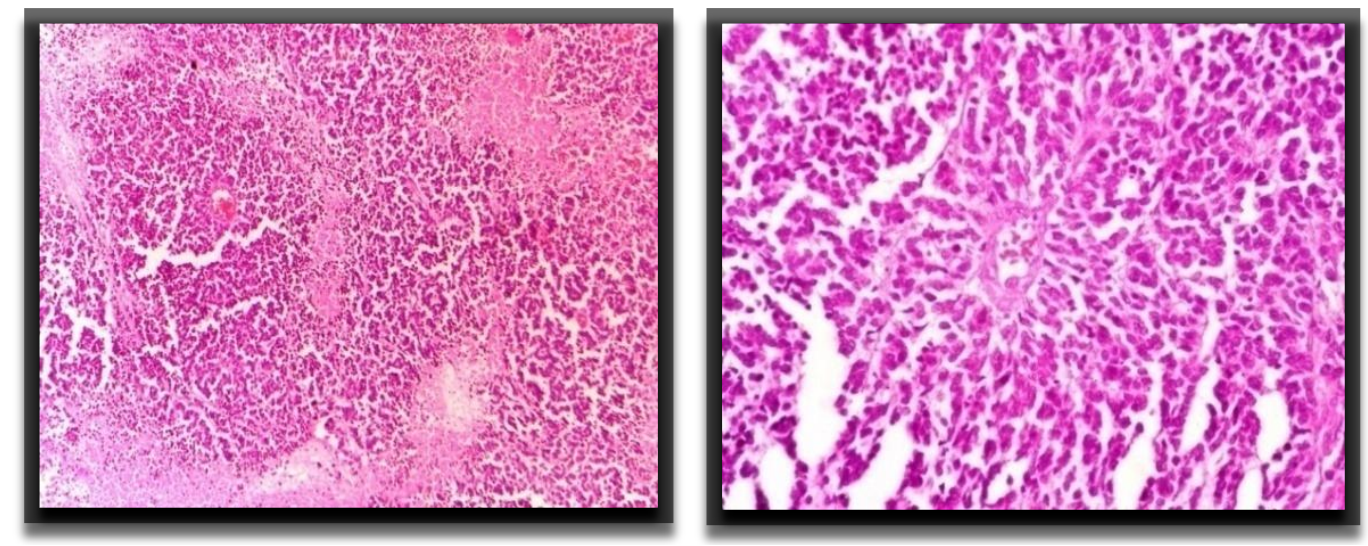

Figure 2:- A AND B. RETINOBLASTOMA: Section shows (H\&E stain; X4) dark areas showing sheets and nests of small blue cells surrounded by pink areas of tumor necrosis and calcification (left figure). Section shows (H\&E stain; X40) tumor cells clustered around blood vessels forming pseudorosettes and necrotic areas; numerous Flexner-Wintersteiner rosettes are also seen (right figure). 


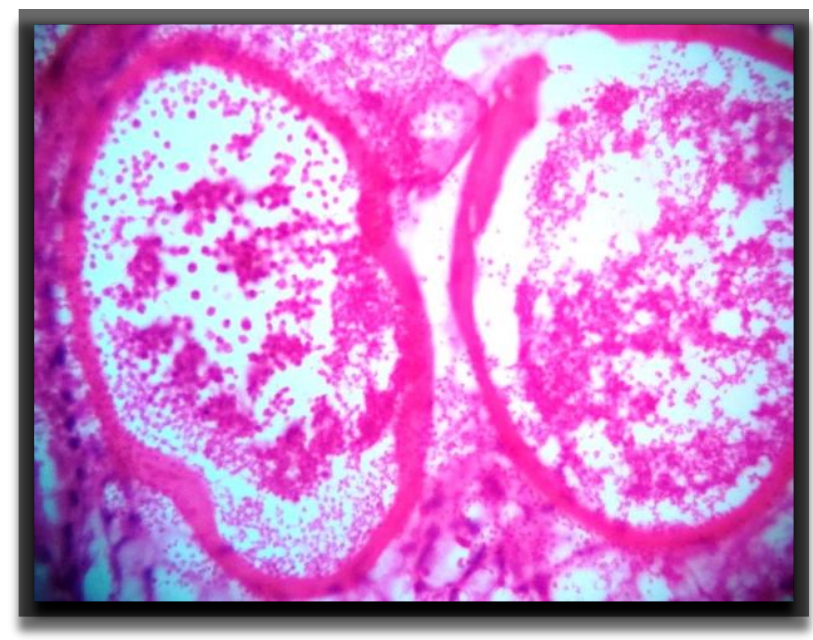

Figure 3:- CONJUNCTIVAL RHINOSPORIDIOSIS: Section shows (H\&E stain; X40) multiple thick walled large spherules filled with thousands of endospores.

\section{Discussion:-}

In present study of 132 cases, 67 cases $(50.75 \%)$ were males suggesting a male preponderance with male to female ratio of 1.03:1 and majority (27 cases, 20.45\%) of the cases belonged to 41 to 50 years of age group. Various studies done by Shah N \& Trivedi N et $\mathrm{al}^{3}$, Bastola P \& Koirala S et $\mathrm{al}^{2}$, Shaikh I et al ${ }^{10}$, Akpe B A \& Omoti AE et al ${ }^{11}$ and Ud-Din $\mathrm{N}$ et $\mathrm{al}^{12}$; found similar results comparable to present study. Chauhan $\mathrm{SC} \& \mathrm{Shah} \mathrm{S}^{1}$ et al reported slight female preponderance. While Pudasini $\mathrm{S}^{13}$, et al, reported 3th and $4^{\text {th }}$ decade as the commonest age group in their studies. In our study, 79 cases $(59.86 \%)$ cases were non neoplastic and 53 cases $(40.14 \%)$ were neoplastic. Various studies found similar results comparable to present study. Ud-Din N, et al ${ }^{12}$, reported neoplastic lesions more in their study. Maximum number of lesions were from eyelids (48 cases,36.36\%) followed by conjunctiva (38 cases, $28.79 \%$ ), and least were seen from lacrimal gland and passages. All the studies indicated that eyelids and conjunctiva were the commonest sites. While Akpe B A \& Omoti $\mathrm{AE}^{11}$ et al and Pudasaini $\mathrm{S}^{13}$ et al reported conjunctival lesions to be commonest.

Among the eyelid lesions, 27 non-neoplastic, 14 benign eyelid lesions and 7 malignant eyelid lesions were reported. Non neoplastic lesions were Inclusion cysts, followed by Non specific inflammation and granulation tissues, Dermoid cyst, Chalazion, Tuberculosis verrucosa cutis and Hidrocystoma. Benign eyelid lesions were Nevocellular nevus, followed by squamous papilloma, benign adnexal tumors, benign fibrous histiocytoma, hemangioma and nneurofibroma. The 7 cases of malignancies were Squamous cell carcinoma (4 cases), Basal cell carcinoma (2 cases), and Meibomian gland carcinoma (1case). Various studies done by Gundogan $\mathrm{CF}^{14}$, et al, Chauhan $\mathrm{S}$, et al ${ }^{15}$, Al-Faky $\mathrm{YH}^{16}$, et al and Paul $\mathrm{S}^{17}$, et al found similar lesions. Many other lesions reported in their studies which were not encountered in our study were lipoma, keratoacanthoma, seborrheic keratosis, cutaneous myxoma, embryonal rhabdomyosarcama and malignant melanomas.

In the present study, 38 lesions were from conjunctiva, majority were diagnosed as CIN, followed by Pterygium, Squamous cell carcinoma, papilloma, cysts, Rhinosporidiosis, Hemangioma and Non specific inflammations \& granulation tissues. Various studies found similar lesions. Other lesions reported in their studies were granuloma pyogenicum, lymphoma, malignant melanoma and sebaceous carcinoma. Of the 34 cases of corneal lesions, majority were diagnosed as Suppurative and inflammatory lesions, followed by Fuch's dystrophy, Staphyloma, Pannus, Lattice dystrophy and aphakic bullous keratoplasty. Nilesh Shah ${ }^{3}$ et al, and Akpe ${ }^{11}$ et al, have reported only one case each of Lattice dystrophy and staphyloma respectively. We received only 5 orbital lesions of epidermal cysts, basal cell carcinoma and neurofibroma. While, other studies also reported Non- Hodgkins lymphoma and Rhabdomyosarcoma of orbit. One case each of Retinoblastoma, Macular amyloidosis, Massive retinal gliosis and Choroid suppurative lesion was reported in intraocular lesions. Other studies only reported retinoblastoma from this site. Only 3 cases were reported from lacrimal system. Study by Nilesh SC ${ }^{3}$, et al reported similar findings with 2 cases of lacrimal sac cysts. However, some studies also reported pleomorphic adenomas and sebaceous adenocarcinomas. 


\section{Conclusion:-}

Many Neoplastic conditions masquerade as or mimic other less aggressive Neoplastic or non-Neoplastic. However some of the histological features are specific and characteristic for each entity. Hence, combination of proper clinical observation and histopathological study gives a conclusive diagnosis. So, we can conclude that all ophthalmic lesions removed surgically should always be subjected to histopathological examination to establish correct diagnosis for further management.

\section{Acknowledgment:-}

I would like to express gratitude and sincere thanks to Dr. (Mrs.) S.S. More, Dr. P.V.Purohit, Dr. P.Shinde, Dr R. S. Patil and Dr.R.M. Shinde for their help and guidance during my study.

\section{References:-}

1. Chauhan S C, Shah S J, Patel A B, Rathod H K, Surve S D, Nasit J G: A Histopathological Study Of Ophthalmic Lesions at a teaching hospital.2012;2(2):133-6.

2. Bastola P , Koirala P , Pokhrel G, Ghimire P, Adhikari RK. A Clinico-Histopathological Study Of Orbital And Ocular Lesions; A Multicenter Study. Journal of Chitwan Medical College 2013;3(4):40-4.

3. Nilesh S, Nitin T, Jigar S. Preinvasive and invasive malignant lesions and nonmalignant-SOL of eye and its adnexa. Indian Journal of Basic and Applied Medical Research. 2014;3(3):363-71.

4. Mills, Stacey E. Chapter24 Eye and ocular adnexa. In : Sternberg's Diagnostic Surgical Pathology, 5th edition. 2010 Mills, Stacey E .pg 966-1156.

5. Mihaela CC, Elena R, Gabriela M, Coroi T, Marinela B. Eyelid tumors: Histopathological and Clinical study performed in County Hospital of Oradea between 2000-2007. Romanian Journal of Morphology and Embryology. 2010;51(1):111-5.

6. Saornil Ma, Becerra E, Méndez MC, Blanco G. Conjunctival Tumors: Arch SocEspOftalmol. 2009; 84:7-22.

7. Kohli M, Shah A, Bhatt S, Aggarwal S. Lacrimal Gland Tumors-A Retrospective Histopathological Study. Gujrat Medical Journal. 2011;66(1):39-41.

8. Yanoff M, Sassani J. Retinoblastoma. In: Ocular Pathology, 6th ed. Elsevier Publication. 2002. P.933-945.

9. Font RL, Croxatto JO, Rao NA. AFIP Atlas of Tumor Pathology. Tumors of the Eye and Ocular Adnexa. Fourth series, fascicle 5. Washington, DC: American Registry of Pathology, 2006.

10. Shaikh IY, Shah FR, Gandhi MB, Shah CK, Shah NR. Ophthalmic Neoplastic lesions- A retrospective study of 4 years.Gujrat medical Joornal.2012;67(2):53-7.

11. Akpe BA, Omoti AE. Histopathology of ocular tumor specimens in Benin City, Nigeria. Journal of Ophthalmic Vision and Research.2009;4(4):2327.

12. Ud-Din N, Mushtaq S, Mamoon N, Khan AH, Malik IA. Morphological spectrum of ophthalmic tumors in northern Pakistan. J Pak Med Assoc. 2001 Jan; 51(1):19-22.

13. Pudasaini S, Kansakar I, Prasad KBR, Rauniyar SK. A histopathological study of ophthalmic lesions.Nepal Med Coll J.2013;15(1):78-80.

14. Gundogan FC, Yolcu U, Tas A, Sahin OF. Eyelid tumors: A clinical data from an eye centre in Ankara, Turkey. Asia Pacific Journal of Cancer prevention.2015;16:4265-9.

15. Chauhan S, Shah S, Solanki P, Shah F, Shah C, Shah N. Accuracy of clinical diagnosis of eyelid lesion in a medical college in Gujrat. Int J Res Med. 2013; 2(1):114-7.

16. Al-Faky YH. Epidemiology of benign eyelid lesions in patients presenting to a teaching hospital.Saudi Journal of Ophthalmology.2012;26:211-6.

17. Paul S. Malignant and benign eyelid lesions in San Fransisco: A study of diverse Urban population. American Journal of Clinical Medicine.2011;8(1):40-6. 